\title{
Nurses’ Deployment Risk And Resilience In Times Of War Conflicts: Checking The Status, Reporting The Future
}

\author{
Minerva Cobus, University Of Benghazi, Libya
}

\begin{abstract}
To date, year August, 2014, as Benghazi, Libya is in a time of conflict depicting a war zone environment, the researcher conducted a study to capture the moment and experiences of foreign national nurses currently deployed in the country performing their duties as healthcare providers. Despite the raised Alert level 4 warning given by the government, meaning "full evacuation mode" from Libya, most nurses refused to be repatriated and stayed to continue serving in Libya. A selected group of sixty-three (63) nurses of different nationalities, working in three (3) different hospitals at the heart of Benghazi, described their present deployment risk level and resilience. Deployment risk level is measured by the Deployment Risk and Resilience Inventory (DRRI) utilizing two of its subscales ( $C$ and $G$ ) - Difficult Living and Working Environment Scale (Deployment Environment) and the Perceived Threat Scale (Deployment Concern). On the other hand, resilience is measured by the Connor-Davidson Scale. Findings revealed lower risk at exposure to events or circumstances representing repeated or day-to-day irritations and pressures related to life, revealed more perceived threat, but highly resilient during deployment at the war zone. Furthermore, no correlation was found between deployment risk (deployment concern) and resilience, negative low correlation between deployment risk (deployment environment) and resilience, and no significant difference in resilience was observed between genders. Checking the nurses' current status of deployment risk and resilience in Libya, gave light to future implications on nursing profession.
\end{abstract}

Keywords: Deployment Risk; Resilience; War

\section{INTRODUCTION}

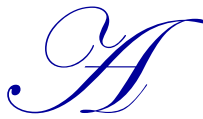

lot has been said about taking risks. Life without risks, they say, is a life not worth living at all. But whether risk-taking is something that individuals consciously seek on a day-to-day basis requires further inquiry. Hazards, after all, remain a part of daily human existence. They are an unavoidable element in life - something everyone has to live with, a constant.

Exposing one's self to hazards is something that a person may not willingly do but there are those who voluntarily leave their comfort zones, welcome the thrill of danger, or push themselves to try things they normally would not do. Reasons for doing so might vary from the whimsical (wanting a simple adrenaline rush) to the essential (addressing the need to pay bills and put food on the table). But putting one's safety on the line to the point of death, however, is certainly a different story.

Risk comes in different forms. Fundamental risk is one type of risk. It is defined as a risk that affects a large number of people in an economy. It is said to be general (as opposed to particular risk which affects only a specific individual). War is an example of fundamental risk.

Working in strife-torn Libya in the northern part of continental Africa is exposing one's self to fundamental risk. The United States warned on July 12, 2014 that the conflict in Libya could become widespread. Since the fall 
of its erstwhile leader Moammar Gaddafi three years ago, Libya's fragile transition to democracy has been battered by infighting and militia violence between Islamist and nationalist factions. Zintan brigades and their allies in the nation's capital Tripoli - the QaaQaa and al-Sawaiq units, including some ex-Gaddafi forces who rebelled - are loosely associated with the nationalist National Forces Alliance movement in the former parliament. Opposing them are a range of Islamist-leaning militias led by Misrata forces, tied to the Justice and Construction Party, an arm of Muslim Brotherhood. Like Zintan, they also claim to be a legitimate forces and inheritors of the 2011 revolt. Heavily armed, they have refused to hand over their guns and sided with competing political forces trying to shape the future of Libya in the messy transition since Gaddafi's four-decade rule over the North African state.

Living in Libya, specifically Benghazi, the country's second-largest city, has become risky. There is the reality of exposure to death and serious injury, fear of abduction or capture by conflicting political forces, uncomfortable/difficult living conditions and environments, among others. And yet despite these tangible dangers to life and limb, foreign nationals, particularly Filipinos, still chose to stay in Libya and face the risks. This is true for most nurses, which comprise a total of 2,103 as of July 30, 2014. To survive, these professionals resort to being extra careful, gauging the level of violence and conflict within the city limits to determine which areas are safe to travel to and which areas should be avoided. Still, others have resorted to purchasing weapons for protection, further made easy by the absence of requisite licensure before purchase. The use of low profile vehicles or hiring taxis driven by locals who know the ins and outs among city streets have become a staple means of getting around. A bond is established with drivers after trust is earned and whose services are availed whenever the needs arise, like getting to and from work, or trips to the grocery store to replenish everyday necessities like food and toiletries. An added benefit to having locals as constant companions is that they often know of brewing disturbances and impending disruptions to peace and order, often starting off as "barbershop gossip", even before the intelligence in the military does. Thus, Filipinos in Benghazi have learned that it is vital to one's survival in the strife-stricken city to fit in with the locals and immerse themselves in the local culture. This is called resiliency.

Resiliency is the ability of a person to deal with tough times. It is the ability to thrive well in the face of adversity, trauma, tragedy, threats or even significant sources of stress. As things may not always turn out the way we want them to, one may experience hurt and disappointment, or worse, trauma or adverse experiences in the midst of stressful situations. Yet in the face of utmost difficulty and suffering, one must possess the ability to recover from those experiences without succumbing to depression or other serious illnesses, whether mental or physical.

It is on this note that this study was conducted. The researcher, currently employed as a nurse-educator at a leading educational institution in Benghazi, is constantly exposed to the risks brought about by the current power struggle in the country's post-Gaddafi era. Despite the Alert level 4 warning (the highest, which means fullevacuation mode) raised by the Philippine government regarding Filipino workers in the country, the researcher, along with a significant number of Filipinos, refused to be repatriated and ignored the mandatory evacuation order. This study determined the deployment risk level of the nurses in Libya and the resilience stratagem they are employing in order to survive.

\section{THEORETICAL FRAMEWORK}

This study is anchored on two (2) theories: Resilience Theory and Adaptation Theory.

Resilience theory addresses the strengths that people and systems demonstrate that enable them to rise above adversity. Resilience is a multifaceted field of study that has been addressed by social workers, psychologists, sociologists, educators and many others over the past few decades. Resilience theorists generally agree that the presence of one or more protective factors can reduce the effects of exposure to adversity. The more protective factors available, the more resilient a person will be.

Adaptation theory, also known as survival theory or survival of the fittest, is a person's ability to adapt to changes in its environment and adjust accordingly over time. Nurses working in Libya lived on this theory. They adapted to the country's current situation despite of the risk. 


\section{RELATED LITERATURE AND STUDIES}

\section{Conflict in Libya}

Libya has warned of a "total collapse" of its health care system as the chaos plaguing the country sent into flight many of the Filipino and Indian staff on whom its hospitals depend. Sixty percent of Libya's hospital staff is health workers from the Philippines while workers from India account for another 20 percent. Even in peacetime, Libya's health services were understaffed and under-equipped. Only Benghazi Medical Centre remains operational, but its capacity has been limited to 300 beds, compared with 1,200 in normal times. (posted at Times of India, August 2, 2014).

\section{Deployment Risk}

As of August, 2014, seventy-seven (77) people have been reported killed and two hundred eighty-nine (289) was wounded in Benghazi's violence. A Filipino worker was kidnapped and found beheaded on July 20, 2014. Manila, Philippines announced Alert Level 4 (full evacuation mode) and chartered ferries that evacuated its nationals, a day after a Filipina nurse was kidnapped and gang raped in Tripoli. In Benghazi, two out of three of the city's main hospitals have shut. Al-Jalla hospital closed, as the army and an Islamist militia tussle to control it.

\section{Resilience}

Ballenger-Browning and Johnson (Retrieved August 24, 2014) cited Bonnano (2006) and Luthar (2007) as regards variations in the definition of resilience include the absence of adverse symptoms following trauma, sustained performance during an intense physical or psychological challenge or maintenance of a positive outlook despite having experienced significant adversity. Several studies conducted by Ballenger-Browning \& Johnson (2010) found that gender is an inconsistent and unreliable predictor of resilience: In a study conducted with crime victims, women reported lower resilience scores; in an earlier study, the result found no significant difference between genders ( $\mathrm{z}$-score=0.05-1.09); yet another study found that women were more resilient compared to men, with this gender difference stronger among older women than younger women.

Bonnano (2010) conducted a two-year longitudinal assessment of $(\mathrm{N}=1828)$ survivors of natural disaster and terrorist attacks found empirical support for four distinct patterns of symptom change: resistance, chronic dysfunction, recovery and resilience. Knowledge of protective factors and risk factors has been consolidated through research on resiliency over 40 years.

Of participants within a household survey $(\mathrm{N}=3,581)$, the prevalence of resilience was $14.5 \%$ one year following such adversities as functional limitation; bereavement or marital separation; or poverty (Netuveli, et al, 2008). Among Operation Enduring Freedom (OEF) and Operation Iraqi Freedom (OIF) veterans ( $N=272)$, the mean resilience score was 77.4 out of 100 for participants without PTSD (using the CD-RISC). Participants with PTSD had a mean score of 59.5 as researched by Pietrzak, Johnson \& Malley (2009).

The study of Singh and Yu (2010) examined the psychometric properties of the Connor-Davidson Resilience Scale (CD-RISC) in the Indian context. The sample comprised of 256 students (age M =22.75, SD = 1.36 years) who completed questionnaire measures of trait resilience (CD-RISC), Big Five Inventory (BFI), Positive and Negative Affect Schedule (PANAS) and life satisfaction (Satisfaction with Life Scale). Original five factor solution did not get confirmation and further a four factor solution, through exploratory factor analysis, was selected as being the most suitable, namely, hardiness, optimism, resourcefulness and purpose. The CD-RISC appeared to be a reliable $(a ́=0.89)$ and valid measure. The concurrent validity results supported hypotheses regarding the relationship of resilience to personality dimensions and life satisfaction and positive and negative effects.

The cited literature and studies described the conflict situation in Libya which exposed deployed nurses to risks resulting to their need to be resilient. The CD-RISC (25-items) was used on different groups revealing varied levels of resilience as point of comparison for this study's result. Test of significant difference between genders was also conducted. 


\section{OBJECTIVE OF THE STUDY}

The objective of this study determined the deployment risk and the resilience of nurses currently working in Libya. Specifically, it aimed to 1) find out deployment risk of nurses in Libya in terms of Deployment Environment and Deployment Concerns, 2) know the resilience the deployed nurses in coping with deployment risk, 3) verify if deployment risk correlates with resilience, and 4) determine if there is significant difference in resilience between genders. The result of the study was analyzed for its implication to nursing profession.

\section{METHODOLOGY}

A descriptive methodology of research is utilized to describe the deployment risk level and the resilience stratagem of nurses currently working in Libya. They were staff nurses providing direct patient care in three (3) hospitals, namely: 1) Al-Jallah hospital, 2) Al-Hawari General Hospital, and Benghazi General Center.

Two-tiered sampling technique was utilized: purposive and convenience. Sixty-three (63) hospital staff nurses at Benghazi, Libya participated in the study. The study was conducted during the months of July 2014 to August 2014 where conflict in Libya is at its height. Majority of the nurse respondents are males (57\%). Almost half (46\%) had been working in Libya for almost two (2) years, $21 \%$ for almost five (5) years and 5\% for as long as 912 years.

\section{DATA GATHERING INSTRUMENTS}

This study utilized two sets of questionnaires.

The first set of the questionnaire is the Deployment Risk and Resilience Inventory (DRRI). Two subscales (C and G) of the DRRI measured the deployment risk level in terms of the Difficult Living and Working Environment Scale (Deployment Environment) and the Perceived Threat Scale (Deployment Concern). The researcher was granted permission for use of DRRI from the United States Department of Veterans Affairs through Dr. Julliette Mott of the Executive Division of the National Center for PTSD.

The Difficult Living and Working Environment Scale (Deployment Environment) is a 14-item subscale which measures the nurses' exposure to events or circumstances representing repeated or day-to-day irritations and pressures related to life during deployment at the war zone. These personal discomforts or deprivations may include the lack of desirable food, lack of privacy, poor living arrangements, uncomfortable climate, cultural difficulties, and constraints to performing one's duties. It uses a 5-point Likert scale ranging from 1 (almost none of the time) to 5 (almost all of the time). Item scores were summed ranging 14-70. Higher scores are indicative of a more difficult living and working environment.

The Perceived Threat Scale (Deployment Concern) is a 12-item subscale which measures the nurses' fear for one's safety and well-being during deployment, especially as a response to potential exposure to warfare (e.g., attacks by enemy combatants, encountering explosive devices), as well as nuclear, biological, and chemical agents (NBCs) in the war zone. It uses a 5-point Likert scale ranging from 1 (strongly disagree) to 5 (strongly agree). Item scores were summed ranging 12-60. Higher scores indicated more perceived threat.

The second set of questionnaire is the Connor-Davidson Resilience Scale (CD-RISC). It is a 25-item scale which measures resilience characteristics including hardiness, personal confidence, tolerance of negative effect, acceptance of change, personal controls and spirituality. It measures the ability to cope with stress and adversity. Respondents rate the items on a 5-point Likert scale ranging from 0 (not true at all') to 4 (true nearly all the time) to indicate how true statements are. Item scores were summed ranging 0-100 and high score lead to high resilience. The researcher was granted permission for the official use of CD-RISC from its authors Jonathan T. Davidson, MD and Kathryn M. Connor, M.D. 


\section{FINDINGS OF THE STUDY}

\section{Nurses’ Deployment Risk}

Deployment Environment

The Nurses' deployment risk in terms of Deployment Environment resulted to a lower sum score of 35 revealing lower risk at exposure to events or circumstances representing repeated or day-to-day irritations and pressures related to life during deployment at the war zone. Population quartile reveals 28,35 and 40 . This means that $25 \%$ of the population scores 28 or less, $50 \%$ scores 35 or less and $75 \%$ scores 40 or less.

The nurses revealed that "some of the time" they feel the climate is uncomfortable. A Libyan climate ranges from $17^{\circ} \mathrm{C}$ to $32^{\circ} \mathrm{C}$ year wide. People can experience too hot or too cold weather such that life is not comfortable. Foods are "some of the time" of poor quality. Living in a war zone subjects one to loud noises like bombing or missiles just around the corner or across the street, thus, one have to be properly attired for immediate evacuation to areas of good shelter and "some of the time" had to deal with hassles like putting on and off heavy or annoying gear. Nurses need not only deal with dangers of war but their daily activities are restricted because of the local religious customs of the Libyans.

\section{Deployment Concerns}

A mean sum score of 43 was revealed indicating high deployment risk in terms of Deployment Concern. As evidenced by their responses to the scale, nurses perceived more threat for one's safety and well-being during deployment. Item scores were summed ranging 12-60; population quartile reveals 36,44 and 48 . This means that $25 \%$ of the population scores 36 or less, $50 \%$ scores 44 or less and $75 \%$ scores 48 or less. It may be said that less than half of Nurses in Libya perceived threat.

Nurses revealed that they are highly concerned that a rocket or mortar might hit their living quarters, or have themselves trapped in the crossfire of rival factions. They are also concerned that they might encounter an explosive device like roadside bomb. As regards threat on their health conditions, they are concerned that they might get infectious disease or get sick due to exposure to nuclear, biological, or chemical (NBC) agents, and worse, get wounded.

\section{Nurses' Resilience}

The deployed Nurses in Libya revealed a mean (sd) CD-RISC score of 77.94 (11.39) which comes close to those under stress group like US Missionaries (Laff et al, 2008) mean of 76.5 (12.8), Hazardous waste and emergency response workers (Calcote et al,2013) group mean of 76.3, and social workers in the vicinity of terrorist attack in NYC 9/11/01(Mc Tighe, 2009), who scored 75.7 (10.9). Item scores were summed ranging 0-100, population quartile reveals 71,77 and 88 . This means that $25 \%$ of the population scores 71 or less, $50 \%$ scores 77 or less, and $75 \%$ scores 88 or less. It may be said that the Nurses in Libya is highly resilient as a whole.

\section{Significant Correlations between Deployment Risk and Resilience}

Table 1. Correlation Between Deployment Risk and Resilience

\begin{tabular}{llc}
\hline & CDRISC & \\
\hline DC (PTS) & Pearson Correlation & 0.008 \\
& p-value & 0.950 \\
\hline DE (DLWES) & Pearson Correlation & $-0.286\left(^{*}\right)$ \\
& p-value & 0.023 \\
\hline
\end{tabular}

* Correlation is significant at the 0.05 level (2-tailed).

Table 1 shows that the relationship between deployment risk (Deployment Concern (PTS) and resilience got a very low coefficient of $r=0.008$ ( $p$-value $=0.950>0.05$ ), this means that no correlation was found between the two variables. On the other hand, a negative weak correlation was tested between deployment risk Deployment 
Environment (DLWES) and resilience with $r=-0.286$ ( $\mathrm{p}$-value $=0.023<0.05)$. This proves that if the deployment environment is not on a high risk, the Nurses experience greater resilience.

\section{Significant Difference in Resilience between Genders}

Table 2. Test of Significant Difference in Resilience Between Genders

\begin{tabular}{ccccc}
\hline & Mean & Difference & p-value & Significance \\
\hline Male & 78.50 & & & Not \\
& & 1.31 & 0.67 & Significant \\
\hline Female & 77.19 & & & \\
\hline
\end{tabular}

Mean (sd) CD-RISC scores were calculated by gender, and no difference was observed in the characteristics evaluated. As depicted in Table 2, the gender comparison revealed a mean score of 78.50 (10.197) for males and 77.19 (12.982) for female ( $\mathrm{p}=0.67)$.

\section{CONCLUSION}

To date, Filipino health care professionals still remain in Libya. While more repatriates continue to trickle out in batches due to the current escalation of violence among opposing political camps (in-fighting mostly concentrated on staking a claim on the city of Benghazi), a significant number has opted to stay citing, primarily, economic woes back in the Philippines. After all, the basic salary of a nurse in Libya is at least four (4) times that of a nurse back home. Thus, the promise of tenure and continued employment has convinced these workers to endure the imminent dangers inherent in living in a war-time scenario.

One might suppose that the persistence of a fundamental risk upon foreign workers in Libya will certainly weigh upon its health care system in more ways than one. While a number continue to stay resilient despite the risks, the question remains: how many are willing to take the place of those who have already joined the exodus out of this struggling North African democracy? Unless its current leaders offer lucrative salaries to health care workers rivaling those offered in neighboring Qatar or Abu Dhabi, or better yet, in western societies such as the U.S. or Canada, first-rate Filipino nurses will surely shun the possibility of deployment in a country where risks to life and limb abound. Libya may now have to bear the misfortune of being a last option for competent nurses seeking employment outside Philippine shores. In the past few years since violence erupted on Libyan soil, some local hospitals have already seen the proliferation of unlicensed nurses, untrained and inexperienced, working side by side with and in the same capacity as their professional counterparts. One might expect this trend to continue and understandably assume a decline in the quality of delivery of health care to the local population. Consequently, as a nurse-educator, the researcher laments a misrepresentation of Filipino health workers who have a reputation for being some of the best in the world.

Curiously, the fate of Filipino nurses currently in Libya depends much on the current state of nursing in the Philippines. Nursing professionals in the Philippines face, not the wrath and peril of war, but conditions that may be just as challenging. Majority of them remain unemployed while those who suffer from below minimum wage compensation, are often times exposed to unfair labor practices such as being overworked (taking care of an average of 25 patients per shift) and are not given appropriate benefits. The Philippine health care system is also plagued by the absence of appropriate infrastructure and modern equipment leaving its professionals at a loss as to how to deliver adequate nursing care to millions of Filipinos in its hospitals and care centers.

The resilience of Filipino nurses might stem from weighing the pros and cons of life in the Philippines versus those in Libya. The lure of employment and better wages come with a probable risk to life in a time of war. This is the risk that some are more than willing to take because some respondents reasoned that such dangers already exist back home, such as the war between insurgents and the military in the southern island of Mindanao, and the slow decay of the peace and order situation evident in most parts of the archipelago. One respondent deduced in the vernacular that he'd be better off dying while employed than unemployed - a statement that may have been said partly in jest but with a painful grain of truth to it. 
Still, it is imperative to cite the Filipino's psyche in this discussion of resilience - his unshakeable devotion to family, his sense of responsibility and loyalty to personal relationships, and his quest towards the realization of a modern Filipino dream that is, to have somebody in the household work abroad and send money and sustenance back home. A lot of Filipinos working in Libya send most of their earnings to support families and relatives in the Philippines. They are heads-of-family, single mothers, or breadwinners whose only resolve is to pacify monthly pleas for monetary provisions that come via text or email. In fact, Filipinos will risk leaving the safety and comforts of their provided accommodations to wander through city streets, not in search of groceries or the latest gadgets, but to look for any money transfer service willing to process their remittances at least once a month. For Filipinos in Libya, Western Union beats KFC in terms of importance. Remittance to family before food cravings is the rule. Despite having a war going on in their midst, it is also this strong sense of "family" that allows Filipino nurses to keep their sanity, so to speak. In the safety of their sometimes cramped quarters, they organize get-togethers and simple parties, having identified themselves as part of a community with shared experiences, fears, responsibilities, and dreams. These reassure them somehow that they are not alone. Further, most of these nursing professionals accede to a shared strategy, treating their experience in Libya as temporary, a stepping stone towards future goals. Some opt to "bite the bullet" for now, pending ample-experience-gained and enough-money-saved until they can ensure employment in "safer" countries.

As it is, the future of Filipino nurses still in Libya lies with a mist of uncertainty hovering above it. Is it really lucrative compensation offers that will convince them to stay longer? Is that the secret to attract future nurse deployments to sustain a crumbling health care system and turn an impending exodus around?

As a nurse-educator for the past thirteen (13) years, the researcher is convinced it is not just a question of profitable compensation. Filipino nurses went through a rigorous training of four years before being given a nursing degree and have been taught that while nursing can be a ticket to landing a high-paying job abroad, it is still, first and foremost, a vocation. Right before one is given the license to practice nursing professionally, the Filipino nurse is made to swear by an oath to "do all in my power to maintain and elevate the standard of my profession....and to devote myself to the welfare of those committed under my care." Since day one in nursing school, nursing college freshmen have been introduced to the heroism of their muse, Florence Nightingale. Her story parallels that of the modern nurse in Libya. Sent from England to Crimea on the northern coast of the Black Sea, Nightingale braved living in a place cursed by a war that saw the death of hundreds of British soldiers and wounded thousands more. A necessity borne of conflict where death and injury were familiar, someone was called to 'nurse' the dying and the infirmed. Nightingale and her colleagues heeded that call. And to further highlight the congruence, one might imagine the same unthinkable risks Nightingale and her war-time contemporaries were exposed to: possible death and serious injury, fear of abduction or capture by conflicting forces, uncomfortable/difficult living conditions, and an utter lack of compensation, much like the risks confronting Filipino nurses in Libya today.

So how much of a risk will scare future deployments and how much risk will convince those who have stayed to finally leave? The answers to these questions are highly personal and remain to be seen. The researcher, herself a first-hand witness to the violent hostilities that toppled the Gaddafi regime, and with God's grace, a future survivor of the current conflict, remains hopeful that all healthcare professionals in the hazardous dispensation of their duties are kept out of harm's way. However, for the nurses who wake up in the morning to bombs exploding nearby, go to work, and sleep to the sound of gunfire as lullabies, resolute and resilient in the midst of a raging war whose end still seems nowhere in sight, the risks are still worth it - at least for now.

\section{AUTHOR INFORMATION}

Minerva Cobus is a Registered Nurse (RN) and a graduate of Master Degree in Nursing. She is pursuing her Doctor of Philosophy at Saint Jude College in Manila, Philippines. She is currently employed as Professor in the Faculty of Nursing in the University Of Benghazi, Libya in the last 5 years. She also teached in two Philippines institutions namely Far Eastern University and Saint Jude College and was honored with Teaching Excellence Awards on separate occasions. 


\section{REFERENCES}

Ballenger-Browning, Kara \& Johnson, Douglas C. Key Facts on Resilience. Naval Center for Combat \& Operational Stress Control June 2010 Demographic and Environmental Predictors

Bonanno GA, Galea S, Bucciarelli A, Vlahov D. Psychological resilience after disaster: New York City in the aftermath of the September 11th terrorist attack. Psychol Sci. Mar 2006;17(3):181-186.

Campbell-Sills L, Forde DR, Stein MB. Demographic and childhood environmental predictors of resilience in a community sample. J Psychiatr Res. Aug 2009;43(12):1007-1012.

Connor KM, Davidson JR. Development of a new resilience scale: the Connor-Davidson Resilience Scale (CDRISC). Depress Anxiety. 2003;18(2):76-82.

Connor-Davidson Resilience Scale or CD-RISC . Davidson JRT, Connor KM. Connor-Davidson Resilience Scale Manual (unpublished 2014. Personal communication from the authors)

Fergus, S., \& Zimmerman, M. (2005). Adolescent resilience: A framework for understanding healthy development in the face of risk. Annual Review of Public Health, (26), 399-419. Retrieved from http://www.csun.edu/ whw2380/438 Spring

Fikkretoglu, Deniz, Brunet, Alain, Piundja, Joaquin, Guay, Stepane, and Pedlar, David. Validation of the Deployment Risk and Resilience Inventory in French-Canadian Veterans: Findings on the Relation Between Deployment Experiences and Postdeployment Health. Canada Journal of Psychiatry 2006: 755763.

Filipino Nurses in Libya Gets Very High Salary http://www.nursingguide.ph/article item695/Filipino_Nurses in Libya Gets Very_High Salary.html

Kamlesh Singh and Xiao-nan Yu, Psychometric Evaluation of the Connor-Davidson Resilience Scale (CD-RISC) in a Sample of Indian Students. *Indian Institute of Technology, Delhi, Indiaand School of Public Health, The Chinese University of Hong Kong, Hong Kong.

King, Susan. What is Adaptation Theory? http://www.ehow.com/about_5105998_adaptation-theory.html

Luthar SS, Cicchetti D, Becker B. The construct of resilience: a critical evaluation and guidelines for future work. Child Dev. May-Jun 2000;71(3):543-562.

Markey, Patrick and Yaakoubi, Aziz El. Libya seeks ceasefire as south Tripoli a militia 'war zone'. TRIPOLI Fri Jul 25,2014

Nurses recall Libya nightmare. Zakat. Twi Circles .net http://twocircles.net/2014aug05/nurses_recall_libya_nightmare.html\#.U-FMGaOiKN8. August 5, 2014

Pietrzak RH, Johnson DC, Goldstein MB, Malley JC, Southwick SM. Psychological resilience and postdeployment social support project against traumatic stress and depressive symptoms in soldiers returning from Operations Enduring Freedom and Iraqi Freedom. J Spec Oper Med. Summer 2009;9(3):67-73.

Resilience theory. (n.d.). Retrieved from http://mypeer.org.au/planning/what-are-peer-basedprograms/theory/resilience-theory/

Resnick, M. (2000). "Protective Factors, Resiliency, and Healthy Youth Development, Philadelphia, Hanley \& Belfus, Inc.” Adolescent Medicine: State of the Art Reviews Vol.II (No.1, February).

Ropeik, David (2002). Risk. New York, New York, USA: Houghton Mifflin Company. ISBN 0-618-14372-6.

Rutter, M. (1985). "Resilience in the face of adversity. Protective factors and resistance to psychiatric disorder." $\mathrm{Br} \mathrm{J}$ Psychiatry 147: 598-611.

Singh, Kamlesh and Yu, Xiao-nan. Psychometric Evaluation of the Connor-Davidson Resilience Scale (CD-RISC) in a Sample of Indian Students. Indian Institute of Technology, Delhi, India, School of Public Health, The Chinese University of Hong Kong, Hong Kong

Toomey, A., Brennan, E. M., \& Friesen, B. (n.d.). Resilience theory as a framework for teaching human development within hbse. Retrieved from http://www.rtc.pdx.edu/PDF/pbResilienceTheory.pdf

Torres, Jim. Risk Classification and Types of Pure Risks. http://ezinearticles.com/?Risk-Classification-and-Typesof-Pure-Risks\&id=4126986, April 18, 2010

US Warns Of 'Widespread Conflict' In Libya. The Times of India, July 13, 2014 